\title{
Evaluation of the Quality of Environmental Impact Assessment Reports Using Lee and Colley Package in Niger Republic
}

\author{
Zakari Mahamadou Mounir $^{1}$ \\ ${ }^{1}$ Department de L'Hygiène, Sécurité et Environnement, Université de Zinder, Niger \\ Correspondence: Zakari Mahamadou Mounir, Department de L’Hygiène, Sécurité et Environnement, Université \\ de Zinder, BP: 656 Zinder, Niger. E-mail: mounir_zakari@yahoo.fr
}

Received: September 19, 2014

Accepted: October 16, $2014 \quad$ Online Published: November 27, 2014

doi:10.5539/mas.v9n1p89

URL: http://dx.doi.org/10.5539/mas.v9n1p89

\begin{abstract}
Until recently, absence or lack of adequate regulations and expertise in environmental studies' field, projects executed in Niger were mainly based on technical and economic aspects; leading to unsatisfactory results with negative consequences on the environment. But, since the adoption of the Framework Law on Environmental management and Environmental Code by the Nigeriens authorities in December 1998; taking into account of environmental issues have become a requirement in all social and economic activities. Thus, Niger as other countries is using Environmental Impact Assessment (EIA) as one of the Environmental management tools. The EIA process is reliant on the information presented in the Environmental Impact Report (EIR). The aim of this paper is to investigate the quality of EIA using Lee and Colley package. The results show slight achievement of EIA, furthermore we also identified factors affecting the EIA in Niger.
\end{abstract}

Keywords: Niger republic, EIA, EIR, Lee and Colley package

\section{Introduction}

Many projects were carried without taking into consideration the environmental issues; as the result of pollution and other environmental problems have grown. Counting from 60s, USA realized that the environmental issues need an attention so as to limit its damage. They legislated that any project must consider environmental standards for sound economic decision making, hence the creation of the NEPA (National Environmental Policy Act) in 1969 and pass as law in January 1970. The aim of NEPA was to force all agencies of the Federal Government to integrate environmental concerns into their planning and decision-making process. Section 120 (2) of the NEPA requires agencies prepare a detailed statement of environmental impacts for Federal actions significantly affecting the human environment. In this way the US environmental policy Act, 1969 was introduced as the first legislation to require EIAs to be carried out. EIA enactment is defined as an effective tool of a proposed action on the environment including all aspects of the natural and human environment. It seeks to compare the various alternatives that are available for any project or program as well as attempting to weigh environmental effects on a common basis with economic costs and benefits in the overall project evaluation. Different definitions have been given for the term Environmental Impact Assessment (EIA). EIA is a "process" that examines the environmental consequences of an action, in advance (Glasson et al., 1994) aiming to ensure the sustainable development.

Niger is one of most underdeveloped countries its socio-economic development is mainly depending on the foreign aid, therefore the country must comply with the international requirements. With the intention of conserving the global environment, the multinational financing institutions have made it mandatory that all development projects should be subjected to EIA before they can be funded (Zakari et al., 2011; Momtaz \& Kabir, 2013). The Environmental Impact Assessment process has been approved extensively in Niger and in the rest of the world. The U.S. model and that of other developed countries share basic principles and reflects commonly agreed-upon approaches to similar problems. Niger Republic like many others developing countries now use procedures for the environmental impact assessment (EIA) of projects which may give rise to significant environmental impacts. Preparing and publishing the Environmental Impact report is an important step in EIA. It is a common agreement that the quality of EIA depends on the quality of EIR. Obviously, majority of developing countries quality of EIA reports does not meet the requirements.

The EIA system was late introduced in the Sub-Sahara-Africa (SSA) regions. The first to introduce national EIA 
systems during the 1980s in SSA were Ghana and South Africa. A few countries, including Niger Republic, followed during the 1990s (Peterson, 2010; Ahmad \& Wood, 2002; Azri et al., 2013; Momtaz \& Kabir, 2013). In Niger, EIA is administered by a central agency, Environmental Impact Assessment Studies Office, known as the 'BEEEI' (Bureau d'Evaluation Environnementale et des Etudes d'Impact). The most important step in setting up the legal framework for the environment in Niger has been the establishment of the Institutionalisation of Environmental Impact Studies by Ordinance 97/01 in 1997 followed by the Framework Law on Environmental Management / Environment Code (Law 98/56). Created under the supervision of ministry of Environment (Ordinance No. 97-001 January 10, 1997), BEEI was instituted in 1999 and its organic laws were adopted in 2000 by Decree No. 2000-369 / PRN / ME /LCD of October 12 concerning its duties, its organization and functioning.

The BEEEI was created by the Niger government to integrate the environmental dimension in projects and programs and to achieve the goals of sustainable development in accordance with the commitments that Niger has contracted through international conventions and agreements. Beside other bodies, BEEEI was aimed to validate environmental and social assessment reports, to organize and facilitate workshops seminars, information and awareness about the environmental and social assessment and education programs relating to the environment, moreover, to achieve by promoting environmental and social audits, to prepare the signature of the Minister of the Environment certificate of environmental and social compliance for the project, activity or program, to monitor compliance of the work planned and standards of environmental and social protection contained in the final report of the environmental and social compliance with laws and regulations evaluation monitored. In addition, BEEEI is meant to track and evaluate the various plans from the environmental and social assessment activities, projects, programs and development plans that are subject; to enforce the administrative procedure for evaluation and review of environmental impacts and the settlement of all legal issues arising. Projects are subject to screening so as to comply with the principles of BEEEI and procedures are as follow: (1) notification of project, (2) location, (3) possible environmental impact (advantages and disadvantages) and (4) executive planning. The BEEEI has the power and obligation to screen a project within three weeks, followed by the ministry of environment for final decision (Zakari et al., 2013; Niger Government, 2006).

Niger and other SSA countries fall in the same EIAs' principles; often their executions are below the international standards. This is due to the fact that poor countries lack required skills and sufficient financial back up to meet the various exigencies that require EIA. There are authors whom suggested that social and cultural factors might have been the reason justifying these difficulties faced by developing countries in achieving an effective EIA.

Therefore, this study is aimed to assess the quality of EIR to understand the effectiveness of EIA in Niger.

\section{Lee and Colley Package}

Methodology and procedure

The Lee \& Colley review package was developed for the review of EIA reports in the UK (Lee et al., 1999). This package had been widely used to undertake reviews of project level of EIA reports and adapted to the EIA procedures of many countries; it is familiar to many professionals in the field of EIA project. It consists of multiple criteria arranged in a four level hierarchical structure consisting of an overall report grade, 4 review areas, 13 categories and 39 sub-categories, which are used to assess the quality of EIA reports. Table 1 shows the review criteria for EIS quality. To evaluate the quality of EIA, several tools were developed by experts; among them those of Lee and Colley are the most widely used in many countries because of their quality and relevance. Therefore in this study, we also used the method developed by Lee and Colley on a 15 samples projects reports carried out between 2008 and 2012 in the water and industry sectors in Niger republic.

Table 1. Review criteria for EIS quality

\begin{tabular}{llll}
\hline \multicolumn{3}{c}{ Criteria for EIS quality } \\
\hline & Description of the development & and baseline & \\
1 & conditions (Area\#1) & 2.3 .1 & Analysis of alternatives \\
1.1 & Description of project & 2.3 .2 & Selection of alternatives \\
1.1 .1 & Background and objectives of project & 2.4 & Community involvement \\
1.1 .2 & EIA aims and scope & 2.4 .1 & Description of community \\
1.1 .3 & Policy and legal framework for EIA & 2.4 .2 & Involvement of community at different stages \\
1.2 & Policy and legal framework for EIA & 2.4 .3 & Approaches of community involvement \\
\hline
\end{tabular}




\begin{tabular}{|c|c|c|c|}
\hline 1.2 .1 & Location of project & 2.4 .4 & Findings of community involvement \\
\hline & & & Environmental Management Plan \\
\hline 1.2 .2 & Project components and activities & 3 & Follow-up (Area\#3) \\
\hline 1.2 .3 & Selection of project alternatives & 3.1 & Mitigation Measures \\
\hline 1.3 & EIA: approach and methodology & 3.1 .1 & Description of adverse Impacts to be mitigated \\
\hline 1.3 .1 & Screening & 3.1 .2 & Mitigation measures with justification \\
\hline 1.3 .2 & Scoping and bounding & 3.1 .3 & $\begin{array}{l}\text { Implementation arrangements of mitigation } \\
\text { measures }\end{array}$ \\
\hline 1.4 & Environmental baseline & 3.1.4 & Residual impacts \\
\hline 1.4 .1 & Natural physical environment & 3.2 & Follow-up: Monitoring program \\
\hline 1.4 .2 & Biological Environment & 3.2 .1 & Parameters/activities to be monitored \\
\hline 1.4 .3 & Socio-economic environment & 3.2 .2 & $\begin{array}{l}\text { Monitoring Plan and implementation } \\
\text { arrangements }\end{array}$ \\
\hline 1.4 .4 & Sources of data with justification & 3.2 .3 & $\begin{array}{l}\text { Reporting and communication of monitoring } \\
\text { result }\end{array}$ \\
\hline 2 & $\begin{array}{l}\text { Identification and evaluation of key impacts } \\
\text { (Area\#2) }\end{array}$ & 4 & Presentation of EIS (Area\#4) \\
\hline 2.1 & Identification of impacts & 4.1 & Layout \\
\hline 2.1.1 & Description of impacts identified at different phases & 4.1 .1 & Logical arrangement of information \\
\hline 2.1 .2 & Beneficial impacts and adverse impacts & 4.1.2 & List of references \\
\hline 2.1.3 & $\begin{array}{l}\text { Methods used for identifying impacts with } \\
\text { justification }\end{array}$ & 4.2 & Presentation \\
\hline 2.2 & Evaluation of impacts & 4.2 .1 & Comprehensible to non-specialist \\
\hline 2.2 .1 & Prediction of impacts & 4.2 .2 & Defining technical terms \\
\hline 2.2 .2 & Significance of impact on affected community & 4.2 .3 & Presented as an integrated whole \\
\hline 2.2 .3 & Significance of impact on bio-physical environment & 4.3 & Executive summary \\
\hline 2.2 .4 & Methods used for evaluation of impacts & 4.3.1 & $\begin{array}{l}\text { Summary of main findings presented in a } \\
\text { non-technical way }\end{array}$ \\
\hline 2.2 .5 & Risk and uncertainties & 4.3.2 & Recommendations \\
\hline 2.3 & Alternatives & & \\
\hline
\end{tabular}

\subsection{Assessment Procedure}

To assess we proceed to assign alphabetical letters (A, B, C, D, E or F) defines as follow in accordance with the quality of information present in each sub- category: $\mathrm{A}=$ for excellent, $\mathrm{B}$ for good, $\mathrm{C}$ for acceptable, $\mathrm{D}$ for poor, $\mathrm{E}$ and $\mathrm{F}$ for very poor and unsatisfied respectively. Then a mean is calculated at the end for each category. The assessment procedure is shown in Figure 1.

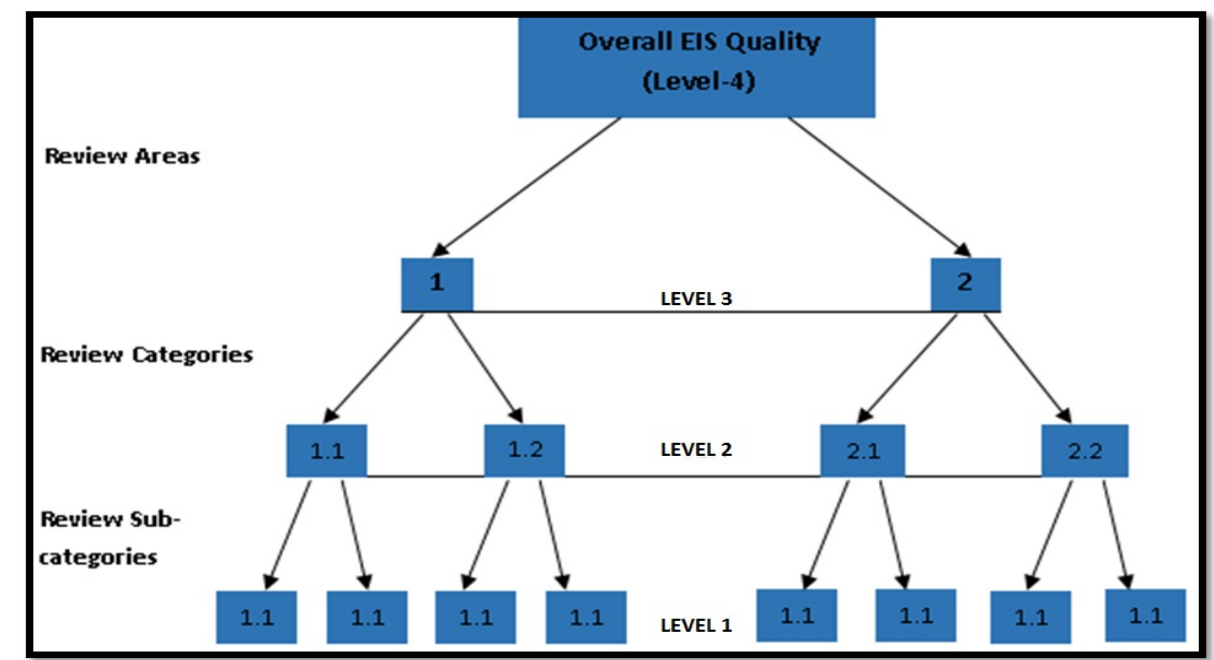

Figure 1. Schematic view of assessment procedure from sub-category to overall assessment of the quality of EIA Reports

Source: Modified after Lee et al. (1999). 


\section{Results and Discussion}

\subsection{Overall quality of EIS in Niger}

Based on the reports, the conditions of satisfaction (level A, B or C) represent $60 \%$ whereas $40 \%$ were reported to be unsatisfied (level grade D and E). However, if we are only to retain high quality reports neglecting shortcomings such as grade $\mathrm{C}$, thus the level of satisfaction would be as low as $27 \%$ while the level of unsatisfied would remain the same $(40 \%)$. The results demonstrated two extremities that is the high rate of the EIR meaning very poor quality and a very low ratio of good quality of EIR. Figure 2 shows in detail the percentage of satisfaction levels.

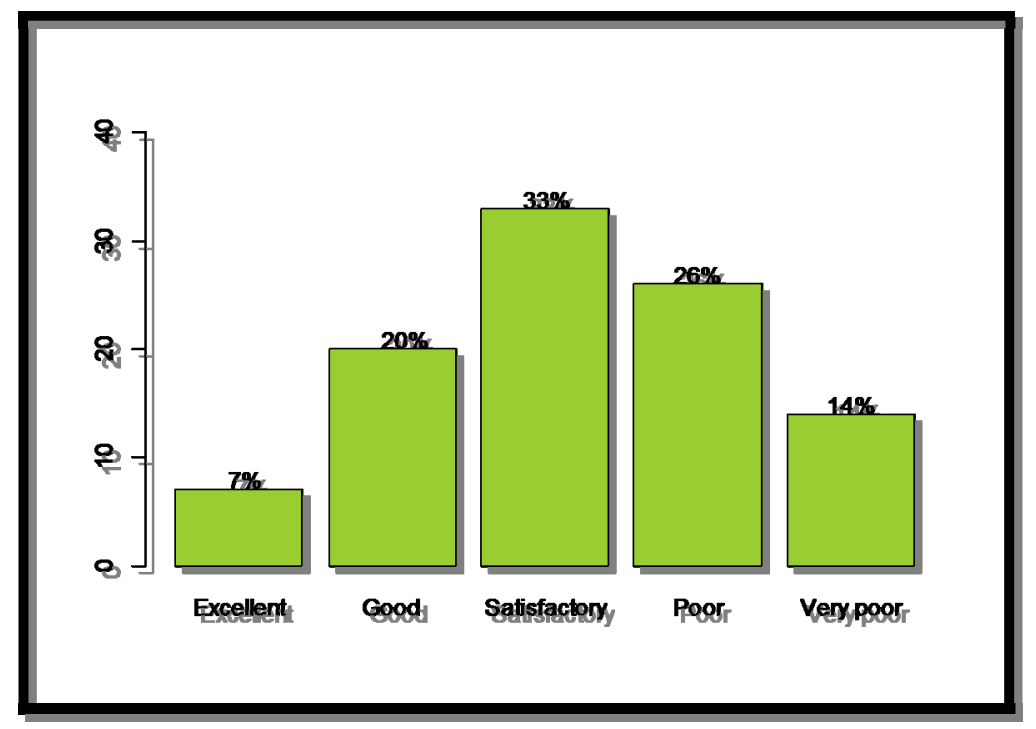

Figure 2. Overall quality of EIS in Niger

\subsection{Review Results of the Quality of EIS by Area}

In Figure 3 we show the performance of each area in EIS based on review results. From the Figure 3, it is obvious that the quality of EIS significantly varies by areas. The graph shows that the performance of area\#1 and area\#4 is better than the area\#2 and area\#3 where area\#4 is the best performed area and area\#2 and area\#3 (in equality) are the worst performed area. For area\#1 and area\#4, there are only $33 \%$ and $20 \%$ unsatisfactory (graded as D and E) EISs respectively. On the other hand, area\#2 and area\#3 involve 54\% unsatisfactory EISs in each case. Therefore the percentage of unsatisfactory EISs for area\#2 and area\#3 are much higher than those of area\#1 and area\#4.

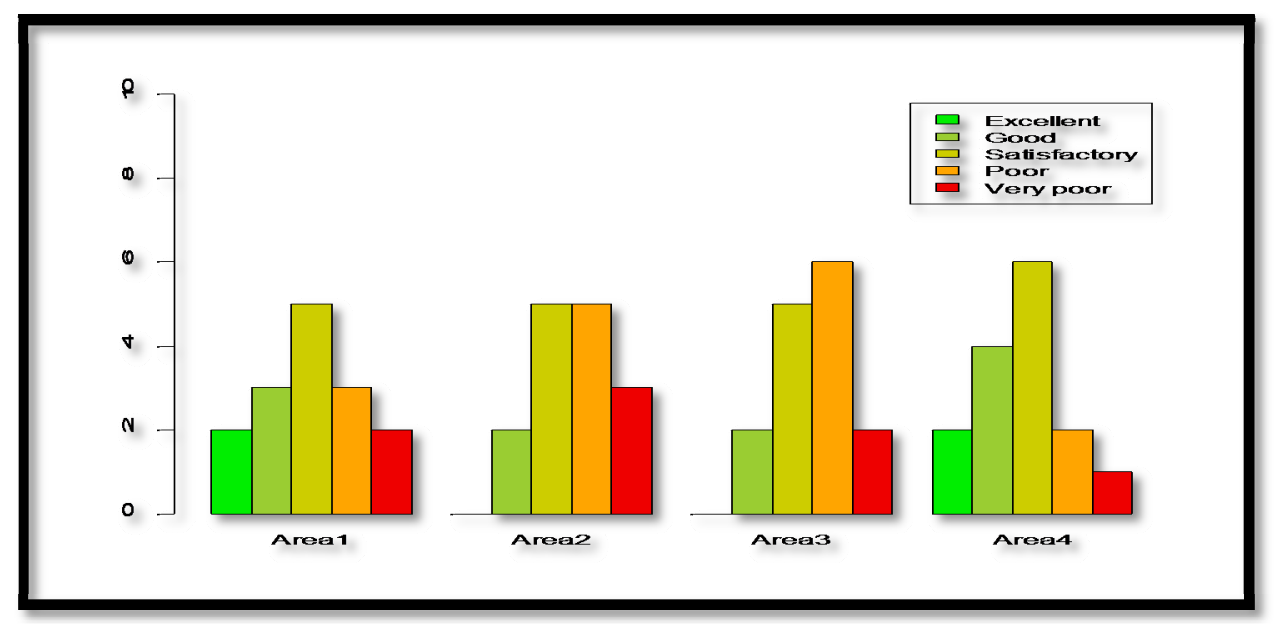

Figure 3. Comparison between areas of EIS 


\subsection{Results by Period and Sectors}

In our study we analyze also the results by period: from 2008 to 2010 and from 2010 to 2012 and the results for the water sector and industry sector. For the period of 2008 to 2010 for water and industry sectors the recorded results $(60 \%$ and $30 \%$ respectively) were satisfactory, therefore an average of $45 \%$. For the period 2010 to 2012 , the satisfy rate is $90 \%$ for water sector and $60 \%$ for industry sector, that is an average of $75 \%$ for this period. Thus, both the EIA reports produced between 2008 and 2010 are of poor quality (up to 55\% of unsatisfactory) and on the other hand the industrial sector was the worse with an average of $55 \%$ unsatisfactory. Based on our study, factors in the case of Niger are responsible for satisfactory and unsatisfactory quality of EIA reports (Supplementary of results of sub-category review "supplementary file").

\section{Factors influencing the quality of EIS in Niger}

The factors that justify the quality of EIA in Niger are identified as followed:

$\checkmark$ Projects implementation by BEEEI,

$\checkmark \quad$ The role played by the partners such as French Agency, Word Bank, ...etc

$\checkmark$ The interdisciplinary team of BEEEI

\section{Factors influencing poor quality of EIS in Niger}

Despite the fact that the average quality of EIS in Niger is satisfactory, a significant proportion have been found to be poor and below the poor category. The major factors influencing the poor quality of EIS are found as followed:

$\checkmark$ Lack of data,

$\checkmark \quad$ Low or lack of qualified skills,

$\checkmark \quad$ Low or Lack of resources

$\checkmark \quad$ Lack of monitoring after decision making,

$\checkmark$ Non awareness of the importance of environmental issues,

$\checkmark$ Corruption, etc.

These results corroborate with the findings reported by Talime (2011) and Zobaidul \& Salim Momtaz, (2010) in Lesotho and Bangladesh respectively. In the case of Niger as in the other developing countries formal scoping was seldom followed and public participation was lacking. Evaluation, mitigation measures and monitoring requirements were also inadequately addressed by most of the EIAs. Indeed, developing countries are weak particularly in impact prediction (Wood, 2003; George, 2000). Although, provisions were for the public the review the EIA reports, however, this was not the cases. This might have been caused by lack of environmental awareness and lack of interests on environmental concerns as the public is only concerned with job creation opportunities and not with the administrative process that goes with job creation. (Doberstein, 2003; Momtaz \& Kabir, 2013) reported that EIA was an imported issue from the western nations to the developing world without proper planning to adapt the concept these nations, therefore it has meet numerous challenges such as cultural, political and administrative differences.

\section{Conclusion}

The EIA is of great importance due to its real implication in the country's economy. Indeed, EIA has showed significant influence on the environment and social economy of developed countries. However, in developing countries, much are yet to be done to the good effectiveness of EIA. Extreme poverty, ignorance and negligence are main obstacles to the behavior changes toward sustainable development that must go with the good environmental issues.

EIA, in Niger did not significantly influenced the decision-making but acts largely as a mitigation exercise for many reasons such as political, social-economic and so on. Many challenges remain in relation to effective application of EIA and the extent to which EIA findings influence development decisions in Niger. These findings may have implications not only for the quality of EIA reports but also for the effectiveness of the entire EIA process.

Our study shows that there are deficiencies in the contents of EIS in Niger despite the fact that some EISs are found to be good and excellent. Further studies are needed to develop sectorial impact assessment guidelines; develop review criteria applicable to Niger. The availability and accessibility of database and the proper approach by the environmental consultants are also needed to achieve good EIA results for better decision 
making.

\section{Acknowledgements}

Authors are grateful to Issoufou Amadou, Ph.D. for his help and comments that substantially improved the article.

\section{References}

Ahmad, B., \& Wood, C. (2002). A comparative evaluation of the EIA systems in Egypt, Turkey and Tunisia. Environmental Impact Assessment Review, 22, 213-234. http://dx.doi.org/10.1016/S0195-9255(02)00004-5

Azri, N. A., Busiadi, R. A., \& Sulaiman, H. (2013). Evaluation of Environmental Impact Assessment (EIA) Systems in GCC States Through Performance Criteria. APCBEE Procedia, 5, $296-305$. http://dx.doi.org/10.1016/j.apcbee.2013.05.051

Doberstein, B. (2003). Environmental capacity-building in a transitional economy: the emergence of EIA capacity in Viet Nam. Impact Assessment and Project Appraisal, 21, 25-42. http://dx.doi.org/10.3152/147154603781766509

George, C. (2000). Comparative Review of Environmental Assessment Procedures and Practice. Environmental Assessment in Developing and Transitional Countries: John Wiley \& Sons, Ltd. pp. 35-70. http://dx.doi.org/10.1002/9781118685570.ch3

Glasson, J., Therivel, R., \& Chadwick, A. (1994). Widening the scope: strategic environmental assessment, chapter 13 in Introduction to environmental impact assessmen, The Natural and Built Environment Series 1. UCL Press: London. Retrieved from www.researchgate.net/.../240728914_Book_reviews

Lee, N., \& Colley. R. (1992) Reviewing the quality of Environmental Assessments. UK: University of Manchester. Retrieved from http://www.sed.manchester.ac.uk/planning/research/publications/wp/ eia/documents/OP24PARTA.pdf

Lee, N., Colley, R., Bonde, J., \& Simpson, J. (1999). Reviewing the quality of Environmental Assessments and Environmental Appraisals. UK: University of Manchester. Retrieved from http://www.sed.man.ac.uk/planning/research/publications/wp/eia/documents/OP55.pdf

Momtaz, S. (2005). Institutionalizing social impact assessment in Bangladesh resource management: limitations and opportunities. Environmental Impact Assessment Review, 25, 33-45. http://dx.doi.org/10.1016/j.eiar.2004.03.002

Momtaz, S., \& Kabir, S. M. Z. (2013). Chapter 2 - Evaluating the Effectiveness of Environmental Impact Assessment System in Developing Countries: The Need for an Integrated Holistic Approach. Evaluating Environmental and Social Impact Assessment in Developing Countries. Boston: Elsevier. pp. 5-28. http://dx.doi.org/10.1016/B978-0-12-408129-1.00002-4

Momtaz, S., \& Kabir, S. M. Z. (2013). Chapter 5 - Evaluating Social Impact Assessment. Evaluating Environmental and Social Impact Assessment in Developing Countries. Boston: Elsevier. pp. 85-111. http://dx.doi.org/10.1016/B978-0-12-408129-1.00005-X

Momtaz, S., \& Kabir, S. M. Z. (2013). Chapter 8 - Evaluating Environmental and Social Impact Assessment: Framework for Effective EIA System. Evaluating Environmental and Social Impact Assessment in Developing Countries. $\quad$ Boston: $\quad$ Elsevier. $\quad$ pp. http://dx.doi.org/10.1016/B978-0-12-408129-1.00008-5

Niger, G. (2006). Guidelines for Environmental Impact Assessment. In: Environment, editor. Niamey, Niger.: Ministère de l'Hydraulique et de l'environnement. Retrieved from www.hydraulique.ne/

Peterson, K. (2010). Quality of environmental impact statements and variability of scrutiny by reviewers. Environmental Impact Assessment Review, 30, 169-176. http://dx.doi.org/10.1016/j.eiar.2009.08.009

Talime, L. A. (2011). A critical review of the quality of environmental impact assessment reports in Lesotho. Bloemfontein, Lesotho: University of Free State, Bloemfontein. Retrieved from http:/etd.uovs.ac.za/ETD-db/theses/available/etd-10192011-141151/unrestricted/TalimeLA.pdf

Wood, C. (2003). Environmental Impact Assessment in Developing Countries: An Overview. Retrieved from http://www.environment-integration.org/Download/D123/Wood.pdf

Zakari, M. M., Chuan, M. M., \& Issoufou, A. (2011). Application of Water Evaluation and Planning (WEAP): A Model to Assess Future Water Demands in the Niger River (In Niger Republic). Modern Applied Science, 5, 
38-49. Retrieved from http://www.ccsenet.org/journal/index.php/mas/article/view/8261

Zakari. M. M, Adamou, M. M., Cheng, S. G., \& Shi. Y. (2013). Impact of droughts and irrigation technique on water resources in the lower valley of the Tarka, Niger. Journal of Environmental Hydrology, 21, 6. Retrieved from http://www.hydroweb.com/protect/pubs/jeh/jeh2013/mounir.pdf

Zobaidul, K., \& Salim, M. S. (2010). The quality of Environmental Impact Statement in Bangladesh; 2010; International Conference Centre Geneva -Switzerland. Retrieved from http:// www.iaia.org

\section{Copyrights}

Copyright for this article is retained by the author(s), with first publication rights granted to the journal.

This is an open-access article distributed under the terms and conditions of the Creative Commons Attribution license (http://creativecommons.org/licenses/by/3.0/). 